\title{
Plasma testosterone and 11-ketotestosterone levels of male pacu Piaractus mesopotamicus (Cypriniformes, Characidae)
}

R. Gazola ${ }^{1}$ and M.I. Borella ${ }^{2}$
${ }^{1}$ Escola de Farmácia e Odontologia de Alfenas, Alfenas, MG, Brasil

${ }^{2}$ Instituto de Ciências Biomédicas, Universidade de São Paulo, São Paulo, SP, Brasil
Correspondence

R. Gazola

Departamento de Ciências

Biológicas

Escola de Farmácia e Odontologia

de Alfenas (EFOA)

Rua Gabriel Monteiro da Silva, 714

37130-000 Alfenas, MG

Brasil

Fax: 55 (035) 299-1063

Publication supported by FAPESP.

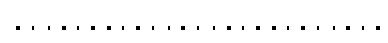

Received June 5, 1996 Accepted October 28, 1997 .....................

\begin{abstract}
The levels of testosterone (T) and 11-ketotestosterone (11-KT) of the South American pacu Piaractus mesopotamicus were determined by radioimmunoassay during two stages of the reproductive cycle, i.e., resting and maturation, and the gonadosomatic index (GSI) was calculated. The highest levels of $\mathrm{T}$ and 11-KT were reached during the maturation stage $(\mathrm{T}=2400 \pm 56 \mathrm{pg} / \mathrm{ml} ; 11-\mathrm{KT}=2300 \pm 60 \mathrm{pg} / \mathrm{ml})$ and lower levels were maintained during the resting period. The rise in androgen levels occurred with the appearance of spermatozoa in the maturation stage, when GSI was highest.
\end{abstract} Key words - Teleost fish

- Testosterone

- 11-Ketotestosterone

- Radioimmunoassay

- Reproductive cycle
Higher vertebrate androgen is produced by the gonads and the adrenal cortex, with the testis being the place where most androgen is synthesized and secreted. The testes of fish can synthesize the androgens testosterone $(\mathrm{T})$, androstenedione and 11-ketotestosterone (11-KT) $(1,2)$.

There has been much discussion about the roles of testosterone and 11-ketotestosterone in male teleosts. It is generally thought that testosterone has an effect on some steps of spermatogenesis such as spermatogonial multiplication and spermatocyte formation (3). The metabolic product of testosterone, released from the body in urine, can also attract the opposite sex and affect sexual behavior (4). In addition, testosterone is a precursor of estrogen biosynthesis and may be implicated in the process of sexual differentiation (5). 11-ketotestosterone markedly stimulates the development of secondary sex characteristics in male teleosts (1). Seasonal changes in serum gonadal steroid hormone levels have been documented in a number of freshwater teleost species (4-9), including female pacu (10). These data have contributed to the understanding of the endocrinological aspects of reproduction in fish.

The pacu, Piaractus mesopotamicus Holmberg, 1887, is a South American migratory fish of great economic importance that inhabits the rivers of the Matogrosso Lowland complex in Central Brazil. In captivity, the pacu shows a pattern of gonadal maturation similar to that seen in nature; however, reproduction does not occur spontaneously in captivity (10).

The purpose of the present investigation was to report the changes in plasma levels of 
the sex steroids testosterone and 11-ketotestosterone in captive male pacu during two stages of the reproductive cycle, i.e., resting $(\mathrm{R})$ and maturation $(\mathrm{M})$.

Male pacu, Piaractus mesopotamicus (N $=30$ ), grown in captivity at the Center of Research and Training in Aquaculture (CEPTA), Pirassununga, SP, Brazil (subtropical zone, $22^{\circ} 02^{\prime} \mathrm{S}, 47^{\circ} 30^{\prime} \mathrm{W}$ ), were utilized for the determination of the testis steroids testosterone and 11-ketotestosterone during the resting and maturation stages of the reproductive cycle. Blood samples (5 $\mathrm{ml} /$ fish) were taken from caudal vessels with heparinized syringes and all fish were weighed and sacrificed. The gonadosomatic index (GSI) was calculated as (gonad weight/ body weight) $x$ 100. Samples of gonads were excised from each fish, fixed in Bouin's solution and processed by routine histological methods for gonadal stage determination. Blood samples were centrifuged and plasma aliquots were stored at $-20^{\circ} \mathrm{C}$. The stored plasma was transported on dry ice to the West Vancouver Laboratory (Vancouver, British Columbia), where the hormone concentrations were determined by radioimmunoassay (RIA).

$\mathrm{T}$ and 11-KT levels were determined directly in unextracted, heat-treated plasma (11). Full details of steroid RIA have been described elsewhere (12). At the 50\% level $\mathrm{T}$ and 11-KT antibodies showed less than $6 \%$ cross-reaction with 11-hydroxytestoster-

Table 1 - Plasma testosterone (T) and 11-ketotestosterone (11-KT) levels during the resting and maturation stages of the gonadal cycle.

Data are reported as means \pm SEM for 15 fish in each group. GSI = (gonad weight/body weight) $x$ 100. ${ }^{*} P<0.01$ compared to resting (StudentNewman-Keuls multiple range test).

\begin{tabular}{lrr}
\hline Stage & Resting & Maturation \\
\hline GSI (\%) & $0.03 \pm 0.02$ & $0.6 \pm 0.1^{*}$ \\
T (pg/ml) & $98 \pm 17$ & $2400 \pm 56^{*}$ \\
$11-\mathrm{KT}(\mathrm{pg} / \mathrm{ml})$ & $250 \pm 30$ & $2300 \pm 60^{*}$
\end{tabular}

one, and less than $2 \%$ with andrenosterone and all other steroids tested. The validity of the assay was confirmed by the demonstration that known quantities of $\mathrm{T}$ and 11-KT added to plasma before sample preparation for RIA were accurate. Precision was determined by analysis of intra-assay and interassay coefficients of variation, which were less than $10 \%$ for the two assays. The sensitivity of the assays was $5 \mathrm{pg} / \mathrm{ml}$. Data are reported as means \pm SEM and were analyzed by analysis of variance (ANOVA) and the Student-Newman-Keuls multiple range test, with the level of significance set at $\mathrm{P}<0.01$.

The profiles of $\mathrm{T}$ and 11-KT as determined by RIA and the GSI of male pacu in the $\mathrm{R}$ and $\mathrm{M}$ stages of the gonadal cycle are shown in Table 1. The plasma values of 11$\mathrm{KT}$ were higher than $\mathrm{T}$ values in the $\mathrm{R}$ stage, whereas in the $M$ stage the $T$ values were higher than 11-KT. However, no significant differences were observed between $\mathrm{T}$ and 11-KT levels in the same stage. The $\mathrm{T}$ and $11-\mathrm{KT}$ values were significantly higher $(\mathrm{P}<0.01)$ during the $\mathrm{M}$ stage $(\mathrm{T}=2400 \pm 56$ $\mathrm{pg} / \mathrm{ml} ; 11-\mathrm{KT}=2300 \pm 60 \mathrm{pg} / \mathrm{ml})$ when GSI was also higher $(0.6 \pm 0.1 \%)$.

Spermatogenesis and spermiation have been considered to be under gonadotropin control in teleosts $(4,13)$. In male teleost fish the major androgens synthesized by the testes appear to be testosterone and 11-ketotestosterone $(4,6,8,14)$.

$\mathrm{T}$ and 11-KT are present in plasma of male pacu in approximately equal amounts in the same stages of the gonadal cycle. Similar results were obtained for the salmonid pink salmon (8), in which $\mathrm{T}$ and 11-KT rise and fall either concomitantly or sometimes with T preceding $11-\mathrm{KT}$ by a month or so.

In male pacu, plasma $\mathrm{T}$ and 11-KT levels were significantly higher during the maturation stage than during the resting stage of the testicular cycle, and a positive correlation between the plasma steroid levels determined and GSI was observed. These results are in 
accordance with those obtained for teleost fish. In Scorpius lineatus, for example, the GSI values are maximal during the period of complete spermatogenesis and 11-KT concentration is higher in males before spawning (15). According to Fostier (4), the levels of $\mathrm{T}$ and 11-KT are characteristically elevated during periods of spermatogenic and spermiogenic activity and fall during reproductive quiescent periods in salmonid species. In Pagrus auratus, plasma $\mathrm{T}$ values increase in fish undergoing spermiation, and plasma 11-KT levels follow a pattern closely similar to that of T levels (16). In Dicentrarchus labrax males which spawn annually, plasma levels of $\mathrm{T}$ and 11-KT are higher during spermiation since the final stages of maturation are regulated by $\mathrm{C} 21$ steroids (6).

\section{Acknowledgments}

We would like to thank Dr. E.M. Donaldson, Head of the West Vancouver Laboratory, for hormone measurements, N. Sukumasavin for technical support and G. Bernardino for providing the fish.

\section{References}

1. Wei-Xin Z (1988). Testosterone and 11oxotestosterone changes during an annual cycle and induced spawning in blunt snout bream (Megalobrama anblycephala). Proceedings of the International Symposium of Guangzhou, PRC, 14-16: 66-72.

2. Vermeulen GJ, Lambert JGD, Van-derLooy MJW \& Goss HJT (1994). Gas chromatographic-mass spectrometric (GC-MS) analysis of gonadal steroids in plasma of the male African catfish, Clarias gariepinus: effect of castration or treatment with gonadotropin releasing hormone analogue. General and Comparative Endocrinology, 96: 288-297.

3. Billard R, Fostier A, Weil C \& Breton B (1982). Endocrine control of spermatogenesis in teleost fish. Canadian Journal of Fisheries and Aquatic Sciences, 39: 6579.

4. Fostier A (1983). The gonadal steroids. In: Hoar WS, Randall DJ \& Donaldson EM (Editors), Fish Physiology. Vol. 9. Part B. Academic Press, New York, 277-346.

5. Liley NR, Breton B, Fostier A \& Tan ESP (1986). Endocrine changes associated with spawning behavior and social stimuli in a wild population of rainbow trout (Salmo gairdneri). General and Comparative Endocrinology, 62: 145-156.
6. Prat F, Zanuy S, Carrillo M, De Mones A \& Fostier A (1990). Seasonal changes in plasma levels of gonadal steroids of sea bass, Dicentrarchus labrax L. General and Comparative Endocrinology, 78: 361-373.

7. Pavlidis $M$, Dimitriou D \& Dessypris A (1994). Testosterone and 17B-estradiol plasma fluctuations throughout spawning period in male and female rainbow trout, Oncorhynchus mykiss (Walbaum), kept under several photoperiod regimes. Annales Zoologici Fennici, 31: 319-327.

8. Dye HM, Sumpter JP, Fagerlund UHM \& Donaldson EM (1986). Changes in reproductive parameters during the spawning migration of pink salmon, Oncorhynchus gorbuscha (Walbaum). Journal of Fish Biology, 29: 167-176.

9. Scott AP \& Sumpter JP (1989). Seasonal variations in testicular germ cell stages and in plasma concentrations of sex steroids in male rainbow trout (Salmo gairdneri) maturing at 2 years old. General and Comparative Endocrinology, 73: 46-58.

10. Gazola R, Borella MI, Donaldson EM, ValSella MV, Sukumasavin N, Fava-DeMoraes F \& Bernardino G (1996). Plasma steroid and corticosteroid levels in female pacu Piaractus mesopotamicus, Teleostei-Characidae. Brazilian Journal of Medical and Biological Research, 29: 659-664.
11. Scott AP, Mackenzie DS \& Stacey NE (1984). Endocrine changes during natural spawning in the white sucker, Catostomus commersoni. General and Comparative Endocrinology, 56: 350-359

12. Van der Kraak G, Dye HM \& Donaldson EM (1984). Effects of LH-RH-ethylamine on plasma sex steroid profile in adult female coho salmon. General and Comparative Endocrinology, 55: 36-45

13. Planas $V$ \& Swanson P (1995). Maturation-associated changes in the response of the salmon testis to the steroidogenic actions of gonadotropins (GTH I and GTH II) in vitro. Biology of Reproduction, 52: 697-704.

14. Kobayashi M, Aida K \& Hanyu I (1986) Annual changes in plasma levels of gonadotropin and steroid hormones in goldfish. Bulletin of the Japanese Society of Scientific Fisheries, 52: 1153-1158.

15. Dedual M \& Pankhurst NW (1992). Plasma steroid hormone concentrations in relation to the reproductive cycle of the sweep Scorpius lineatus (Kyphodidae) caught from the wild. Australian Journal of Marine and Freshwater Research, 43: 753-763.

16. Carragher JF \& Pankhurst NW (1993) Plasma levels of sex steroids during sexual maturation of snapper, Pagrus auratus (Sparidae), caught from the wild. Aquaculture, 109: 375-388. 